Stanton, N. A.; Chambers, P. R. G. \& Piggott, J. (2001) Situational awareness and safety. Safety Science 39 189-204.

\title{
Situational Awareness and Safety
}

\begin{tabular}{|c|c|c|}
\hline Neville A. Stanton* & Peter R. G. Chambers & John Piggott \\
Department of Design & BG Transco plc & BG Technology Ltd \\
Brunel University & Norgas House & Gas R\&T Centre \\
Runnymede Campus & PO Box 1GB & Ashby Road \\
Egham & Killingworth & Loughborough \\
Surrey & Newcastle upon Tyne & Leicestershire \\
TW20 0JZ & NE99 1GB & LE11 3GR \\
\hline
\end{tabular}

This paper considers the applicability of situation awareness concepts to safety in the control of complex systems. Much of the research to date has been conducted in aviation, which has obvious safety implications. It is argued that the concepts could be extended to other safety critical domains. The paper presents three theories of situational awareness: the three-level model, the interactive sub-systems approach, and the perceptual cycle. The difference between these theories is the extent to which they emphasise process or product as indicative of situational awareness. Some data from other studies are discussed, to consider the negative effects of losing situational awareness as this has serious safety implications. Finally, the application of situational awareness to system design, and training are presented.

KEYWORDS: Situational Awareness, Errors, Cognitive Models, Teams, Design.

*Corresponding author

Voice: +44 (0) 1784-431341

Fax: +44 (0) 1784439515

Email: neville.stanton@brunel.ac.uk 


\section{History of the Concept}

According to Gilson (1995), the concept of situational awareness was identified during World War I by Oswald Boelke who realised 'the importance of gaining an awareness of the enemy before the enemy gained a similar awareness, and devised methods for accomplishing this.' This idea of separation between the human operators understanding of system status and actual system status is at the crux of the definition of situational awareness (Woods, 1988). The idea did not receive much attention in the technical and academic literature until the late 1980's, but has become a hot topic ever since. One explanation for the considerable time lag between initial identification of the phenomena and maturity of the concept is the degree to which a real problem was perceived. The initial push for research and development came from the aviation industry, where there is considerable pressure for pilots and air traffic controllers to develop better situational awareness (Jenson, 1997). This call has arisen with the increased realisation that system design is no longer optimised for human operation and, under some conditions, has 'overstepped the human's capability to keep track.' It is perhaps no surprise that the coming of age of the research into situational awareness is closely coupled with the increase in the degree of automation in flight control. Indeed, many researchers cite the glass cockpit (i.e. the replacement of the traditional cockpit comprising a multitude of dials accessed in parallel with a small number of CRT displays requiring the pilot to access displays sequentially) as responsible for psychologically distancing the pilots from their aircraft and the situation (Norman, 1991; Adams, Tenney \& Pew, 1995). As one pilot put it 'With old cockpits the workload was high but you were always aware of what's going on.’ (Adams, Tenney \& Pew, 1995).

Woods (1988) points out that in order for people to maintain an adequate awareness of system status, they need to track the development of events (indicated as the broken line steps in figure one) as they gradually unfold (as illustrated in the left-hand side of figure one as the bold line steps). He argues that incidents evolve by the propagation of disturbances over time. These problems become exacerbated if human controllers fail to adapt to new events. This can lead to an uncoupling of system state and the human operators understanding of system state (as illustrated in the right-hand side of figure one where the dotted line (human situational awareness) departs from the bold line (actual system state)). The resulting control actions on the basis of mistaken situational awareness could, potentially, make a bad incident even worse. Such as the events precipitating the explosion at Chernobyl (Reason, 1990).
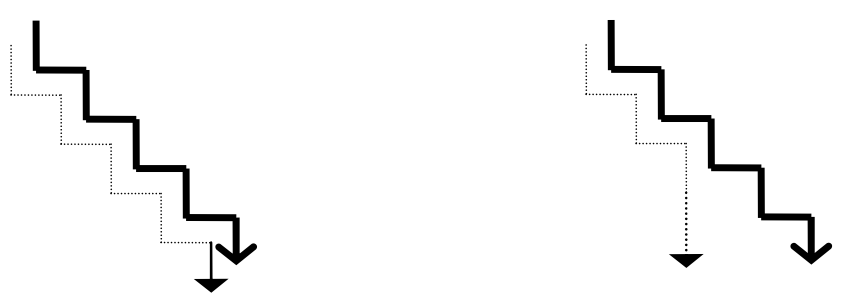

Figure one. Tracking the situation (after Woods, 1988)

The importance of situational awareness in maintaining safe control of an aircraft cannot be overstated. One review of over 200 aircraft accidents found that poor 
situational awareness was the main causal factor (Hartel, Smith \& Prince, 1991). Yet some have criticised the concept for being too subjective (Gilson, 1995), too intuitive (Flach, 1995), and lacking a coherent definition (Sarter \& Woods, 1991). Other researchers have countered these accusations, arguing that situational awareness is a useful concept with considerable significance for operational settings (Gilson, 1995). Despite having its roots in aviation, it has been suggested that the concept is equally applicable to human supervisory control for land based industries (Kaber \& Endsley, 1998). This argument is centred on the shared characteristics of the two operational environments (Kaber \& Endsley, 1998), namely:

(i) Multiple goals to be pursued by operators simultaneously;

(ii) Multiple tasks having different relevance to goals competing for the operators attention;

(iii) Operator performance under time stress and negative consequences associated with poor performance.

It is also argued that problems in human supervisory control may be due to poor situational awareness (Kaber \& Endsley, 1998), such as:

(i) Failure to detect critical cues regarding the state of the system;

(ii) Failure to interpret the meaning of information perceived via SCADA technology;

(iii) Failure to understand individual task responsibilities and the responsibilities of others;

(iv) Failure to communicate with other operators in the team;

(v) Failure to communicate with other teams.

Given the potential importance and applicability of the concept to safety, it is important to review the state-of-the-art and consider how the concept might be extended to all manner of application domains, especially as it has been argued that even small lapses in situational awareness could have serious repercussions (Endsely, 1995).

\section{Definitions of Situational Awareness}

The terms situation(al) awareness, situation(al) assessment and situation(al) measurement are rife in the literature. For simplicities sake, the term 'situational' has been adopted in this paper as the terms appear interchangeable. Researchers and practitioners in this field have attempted to clear up the ambiguities in the definition of situational awareness (often abbreviated to SA in the literature). At a very simple level, situational awareness is an appropriate awareness of a situation (Smith \& Hancock, 1995). Three main definitions dominate. The first of these centres around an information processing framework, the second emphasises the reflective quality, and the third presents an embedded world view. Each definition will be presented in turn, followed by a brief analysis of the differences and an integration of the approaches taken.

Situational awareness is the perception of the elements in the environment within a volume of time and space, the comprehension of their meaning and a projection of their status in the near future (Endsley, 1988). 
Situational awareness is the conscious dynamic reflection on the situation by an individual. It provides dynamic orientation to the situation, the opportunity to reflect not only the past, present and future, but the potential features of the situation. The dynamic reflection contains logical-conceptual, imaginative, conscious and unconscious components which enables individuals to develop mental models of external events (Bedny \& Meister, 1999).

Situational awareness is the invariant in the agent-environment system that generates the momentary knowledge and behaviour required to attain the goals specified by an arbiter of performance in the environment (Smith \& Hancock, 1995).

Whilst these definitions may seem, at first sight, to be at odds with each other, these have been integrated in figure two. This is done by presenting five main elements in a system: the person (comprising three main sub-systems: working memory, mental models (drawing on knowledge, skills and experience) and reflection together with projection), the world (comprising many sub-systems not mentioned here). The figure also indicates an interaction between the two main system elements (i.e. the person and the world).

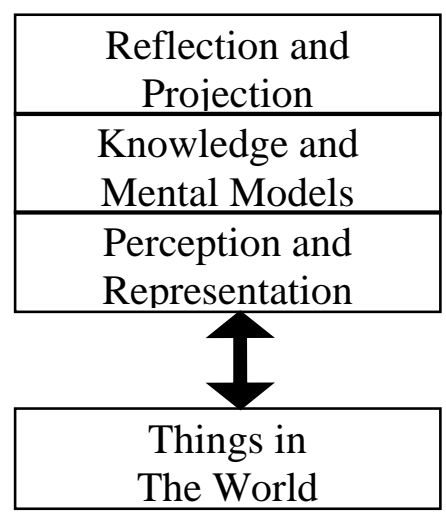

Figure two: Integrating situational awareness definitions into a systems approach.

In reviewing the three definitions of situational awareness proffered earlier, each can be explained with reference to figure two. Endsley's (1988) definition emphasises mainly perception and understanding of the world with some aspect of future projection. By contrast, Smith \& Hancock (1998) define situational awareness mainly in terms of the interaction between the person and the world, thus it focuses largely on the way in which the two main system elements work together. Bedney \& Meister (1999) emphasise the reflective aspect of situational awareness particularly the relation with mental models with some reference to understanding of present system. The main differences between the definitions are, then, the degree to which they distinguish between the importance of working memory or global workspace or more long-term knowledge or the nature of the interaction in determining situational awareness. These differences can be characterised as either being mainly concerned with the process of acquiring situational awareness or mainly being concerned with the product of situational awareness. It is highly likely that both have important parts to play in developing a clear understanding of situational awareness. The information processing paradigm dominates theoretical work on situational awareness, but the more applied focus of naturalistic decision making has been associated with the rise 
in popularity of situational awareness research (Zsambok, 1997). It seems as if there is a hierarchical relationship between the concepts, situational awareness is subsumed under naturalistic decision making which itself is subsumed under more general information processing. There is certainly an inheritance of underlying psychological theory and study between the concepts.

\section{Theories of Situational Awareness}

The theories of situational awareness are strongly associated with the definitions that have given rise to the concept and the methods of assessing situational awareness in the world. Three main theoretical approaches dominate: the information processing approach, the activity approach and the ecological approach. The information processing approach has been best represented by Endsley's (1995) theoretical threelevel model of situational awareness. This presents an unfolding of situational awareness as higher-order cognitive processing is performed. The activity theoretic approach presents situational awareness as only one of many components of reflective-orientational activity, as described by Bedny \& Meister (1999). The model of the perceptual cycle presents situational awareness as a dynamic interaction between humans and their environment. Proponents of this approach suggest that it is the context of the interaction that defines the situational awareness (Smith \& Hancock, 1995; Adams, Tenney \& Pew, 1995). Each of these views will be presented in turn.

\subsection{Three-level model}

The three-level model of situational awareness (Endsley, 1995) was developed initially to understand aviation tasks (e.g. piloting aircraft and air traffic control where people are required to keep up-to-date with dynamically changing environment), but it is argued that it could been extended into other domains such as power generation, petro-chemical, nuclear, command and control, medicine, etc. In essence, any task that requires people to keep track of events is a potential candidate for situational assessment research and application. Endsley's model is arranged into three hierarchical levels of situational assessment, each stage being a necessary (but not sufficient) precursor to the next, higher, level. This model follows a chain of information processing, from perception, through interpretation, to prediction. From the lowest to the highest, the levels of situational awareness are as follows: 
Level 1 SA: Perception of the elements in the environment

This is the lowest level of situational awareness and is associated with the pilot's perception of information from aircraft instrumentation, the behaviour of the aircraft, other people in the cockpit, other aircraft in the sky, the terrain, air traffic control. No interpretation of the data is performed at this stage, all it is intended to represent is the initial receipt of information in its raw form. If data could be elicited at this stage, the operator might be able to confirm the status of a particular variable (such as air speed, altitude, engine revolutions, fuel status, location, heading, etc.) but will not have integrated the data.

Level 2 SA: Comprehension of the current situation

Comprehension may follow on from the perception of the elements (not necessarily though) if the data can be integrated and synthesised to produce an understanding of the relevance to the pilot's tasks. It is argued that comprehension is essential to understand the significance of the elements and to gain a picture of what is going on (e.g. time and distance with fuel available, tactical status of threats, mission status, etc.). In this way, the pilot is able to make judgements about whether their actions have the intended outcomes. Endsley argues that the degree of comprehension achieved is a mark of the expertise of the pilot. Less skilled individuals may achieve a lower Level 2 SA despite achieving the same Level 1 SA as their more skilled counterparts.

Level 3 SA: Prediction of future status

This is the highest level of situational awareness and is associated with the ability to project the future of the elements in the environment (e.g. projected potential aircraft conflicts). Accuracy of the prediction is highly dependent upon the accuracy of level 1 SA and level 2 SA . Anticipation of the projected future situation provides the pilot (and air traffic controller) with time to resolve conflicts and plan a course of action to meet their goals. Similarly, other personnel performing time critical activities rely heavily upon prediction to anticipate problems and deal with them in a timely manner.

An illustration of Endsley's model is presented in figure three. As the figure shows, situational awareness is embedded within a cognitive model of human activity in a dynamic system. Endsley has indicated how situational awareness is influenced by task factors and individual factors. This explains why two people faced with different tasks factors might arrive at different conclusions as might people with different abilities, experience, and training. 


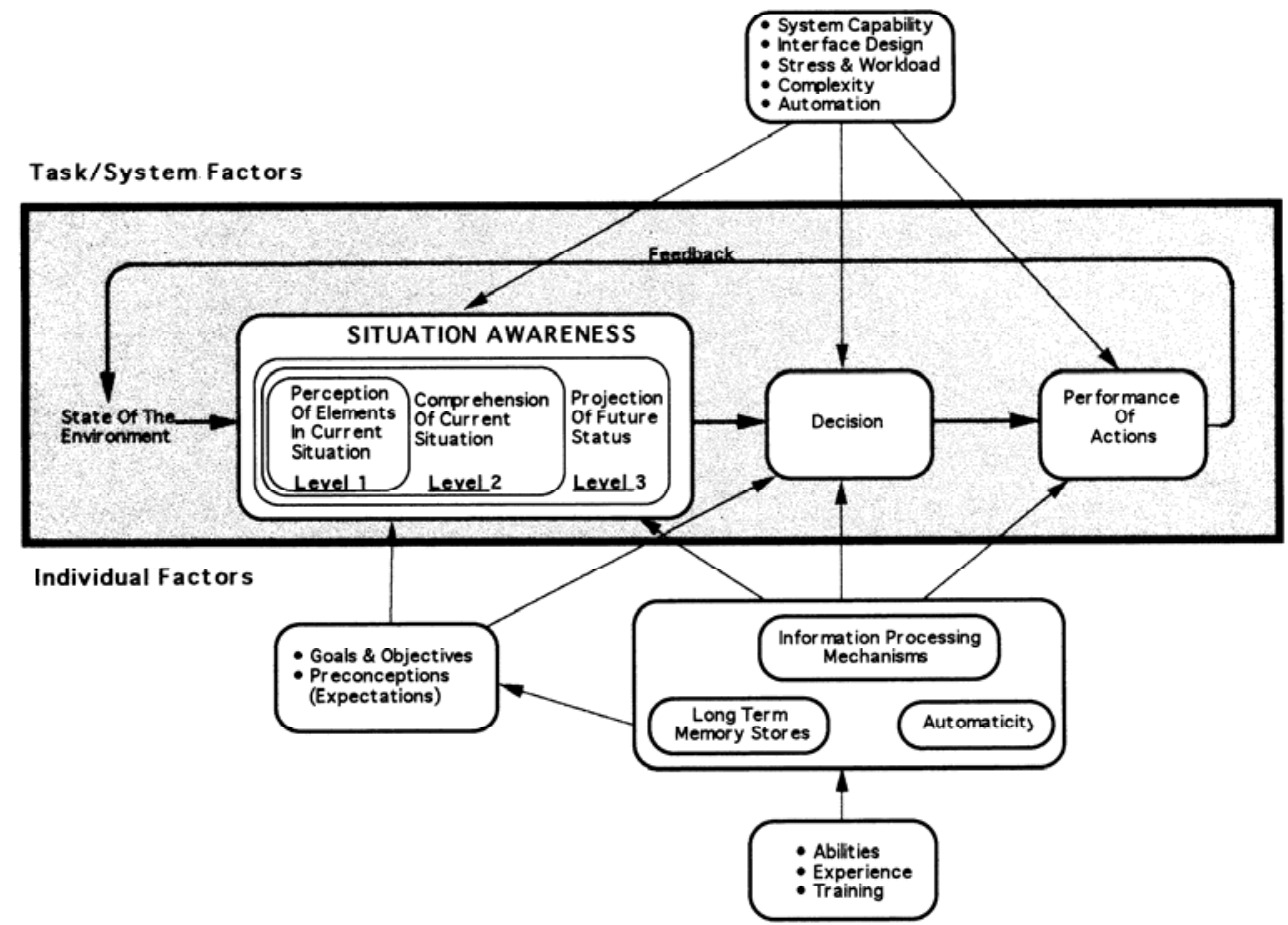

Figure three: The three-level model of situational awareness (from Endsley \& Smolensky, 1998).

The three-level model proposed by Endsley (1995) shows an increasing degree of awareness as the information is processed at the higher levels. She points out that comprehension involves integrating external data with knowledge and goals, which in turn informs the projected status of the world. The model seems generic, as it is based on general cognitive processes, offering a broad theoretical construct with many application areas. In the domain of dynamic systems, Endsley proposes that situational awareness is normally discussed in terms of system specific subcategories, such as mode awareness, spatial awareness and time awareness.

\subsection{Interactive sub-systems}

The second approach is based on a theory of activity presented by Bedney \& Meister (1999). This theory posits a functional model of orientational activity that comprises eight main function blocks. This is an interactive, cognitive, sub-systems approach that has only recently been introduced to the Western world from Russia. As an information processing approach, it is different in the respect that it does not specify processes that are traditional to cognitive psychology, such as perception, memory, thinking, and action execution. Rather it proposes that the extent to which processes are involved is dependent on the nature of the task and the goals of the individual. This argument looks rather similar to a matrix approach to cognitive psychology, comprising two main dimensions of processes and functions. As the processes are well reported in the literature (e.g. Eysenck \& Keane, 1995; Wickens, 1994), we will concentrate on the functions here. In situational assessment, Bedny \& Meister (1999) argue that the functional blocks will orientate toward the task of comprehending the 
meaning of the situation. The model they present shows eight functional blocks connected through feed-forwards and feedback loops, as illustrated in figure four.

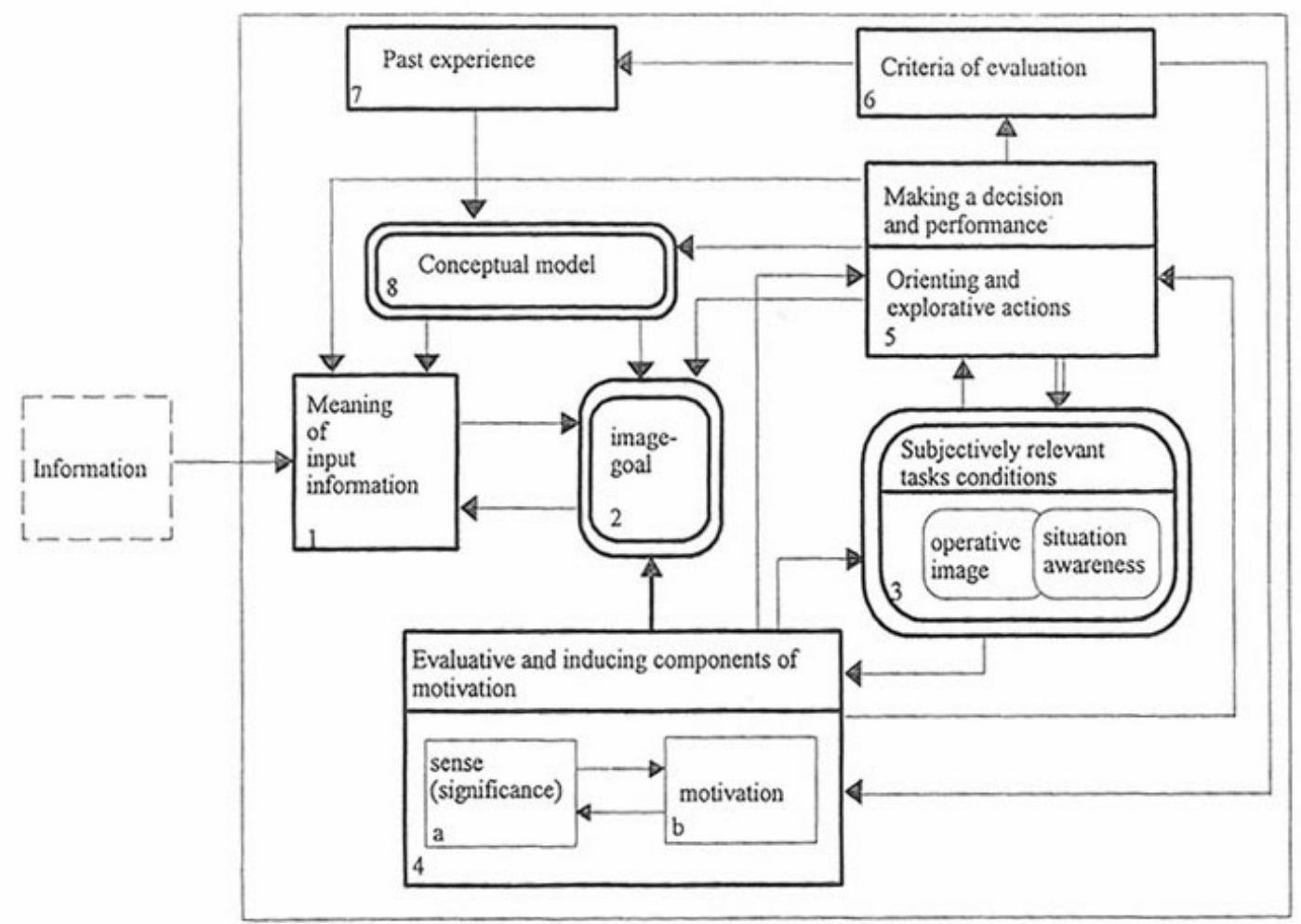

Figure four. An interactive sub-systems approach to situational assessment (from Bedny \& Meister, 1999)

As figure four shows, each function block has a specific task in the development of situational awareness and structure of activity. The content of each block will depend upon the nature of the dynamic situation. A summary of the role of each block is presented in table one. 


\begin{tabular}{|l|l|l|l|}
\hline Block & Function & $\begin{array}{l}\text { Input } \\
\text { Block }\end{array}$ & Summary of role \\
\hline 1 & Meaning & $0,2,5,7$ & Interpretation of information from world \\
\hline 2 & Image & $1,4,5,8$ & Conceptual 'image' of information-task-goal \\
\hline 3 & Conditions & 4,5 & Dynamic reflection of situation and task \\
\hline 4 & Evaluation & 3,6 & Comparing motivation and performance \\
\hline 5 & Performance & 3,4 & Interacting with the world \\
\hline 6 & Criteria & 4,5 & Determining relevant criteria for evaluation \\
\hline 7 & Experience & 6 & Modify experience to interpret new information \\
\hline 8 & Model & 7 & Modify world model to interpret new information \\
\hline
\end{tabular}

Table one. Summary of the role and inputs to function blocks shown in figure four.

In the theory of activity described by Bedny \& Meister (1999), new information arrives via the sensory-perceptual systems to function block 1 to be interpreted through the individuals conceptual model of the world (function block 8), their 'image' of the purpose of the task goals (function block 2) and their orientation about what type of activity is required (function block 5). This interpretation then informs the person's 'pure' image of the task goals (function block 2). The individual determines which features of the world are pertinent in function block 3 on the basis of the significance and motivation toward the task goals (function block 4) as well as their engagement with the world (function block 5). The extent to which they engage the task goals are determined in function block 2, which in turn are influenced by the criteria developed for evaluation (function block 6) and the current state of the world (function block 3). The outcome of this evaluation directs performance and the persons engagement with the work (function block 5) from which further criteria are developed (function block 6). Interaction with the world is stored as experience (function block 7) and informs the individuals stored representation of the world function block 8). As the interactive model shows, information from the person's actions and their conceptual model (function blocks 5 and 8 respectively) feedforward into the new interpretation of information from the world (function block 1).

As a systems theory of activity, the model looks incomplete. Two glaring problems seem to be the lack of feed-forward from function block 2 (e.g. a direct link to function block 4) and no link to the world from function block 5. Despite this, the interacting sub-systems does present an appealing description of human cognition. Bedny \& Meister (1999) argue that the key processes that produce situational awareness are the combination of the conceptual model (function block 8), the imagegoal (function block 2) and the subjectively relevant task conditions (functional block 3 ). They suggest that the first two function block are relatively stable (i.e. function blocks 2 and 8 ) whereas the latter is much more manipulable (i.e. function block 3). If what the human operator regards as subjectively relevant is misguided, then a faulty orientation to the situation can result. This may be regarded as loss of an appropriate situational awareness. Once set on this path, through which all future orientation and exploratory activity is guided, it may be difficult to re-orientate the human operator to evaluate what is objectively important and develop a more realistic reflection of the situation. 


\subsection{The perceptual cycle}

The alternative view of situational awareness is that it is neither resident in the world nor in the person, but that it resides through the interaction of the person with the world (Smith \& Hancock, 1995). This approach is a development of Neisser's (1976) model of the perceptual cycle (Adams, Tenney \& Pew, 1995). Adams et al (1995) argue that process-product dichotomy of situational awareness embraced in differing degrees by the theorists can be taken in context through consideration of a theory of human information processing. Process refers to the perceptual and cognitive activities involved in revising the state of situational awareness whereas product refers to the state of situational awareness with regard to available information and knowledge. In Neisser's (1976) seminal work ‘Cognition and Reality’ he puts forward a view of how human thought is closely coupled with a persons interaction with the world. He argued that knowledge of how the world works (e.g. mental models) leads to the anticipation of certain kinds of information, which in turn directs behaviour to seek out certain kinds of information and provide a ready means of interpretation. During the course of events, as the environment is sampled, the information serves to up date and modify the internal, cognitive, schema of the world, which will again direct further search. An illustration of the perceptual cycle is shown in figure five.

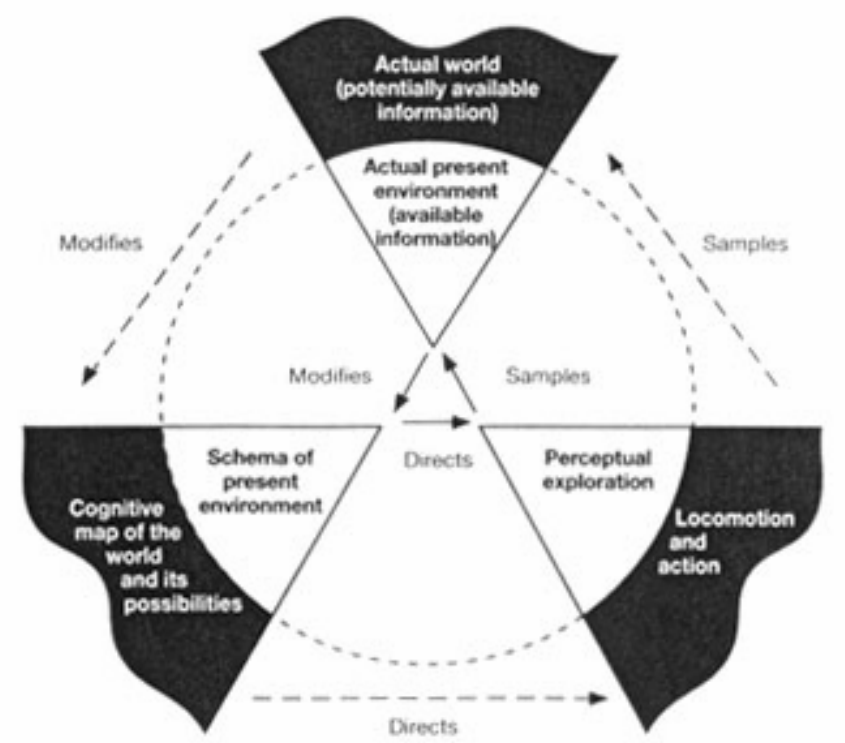

Figure five: Expanded view of the perceptual cycle. The inner circle depicts the perceptual cycle and the outer circle depicts the general exploratory cycle (from Neisser, 1976).

The perceptual cycle can be used to explain human information processing in control rooms. For example (assuming that the control room engineer has the correct knowledge of the system they are controlling), their mental model will enable them to anticipate events (such as the morning and evening peaks in demand), search for confirmatory evidence (look at the forecasts), direct a course of action (direct gas into storage) and continually check that the outcome is as expected (system pressures are in line with anticipated demand). If they uncover some data they do not expect (such 
as a rise or fall in pressures not in line with those anticipated) they are required to source a wider knowledge of the world to consider possible explanations that will direct future search activities. The completeness of the model is in the description of process (the cyclical nature of sampling the world) and product (the updating of the world model at any point in time).

\subsection{Summary of the theories}

There appears to be an element of truth in all of the theories. The embedded interactive model (Smith \& Hancock, 1995; Adams, Tenney \& Pew, 1995) is good at explaining the dynamic aspect of situational awareness, such as how the momentary knowledge is updated and how the search for information from the world is sought. This presents a high-level view of a person interacting with their environment. Systems based approaches seem particularly useful in this respect. The cognitive subsystems approach (Bedney \& Meister, 1999) is ideal for considering underlying functions and how they might interact. This view focuses on the individual, to specify the information processing activities inside their head. The three-level model of situational awareness (Endsley, 1995) offers a functional model for assessing different degrees of insight in a pragmatic manner. This offers a direction of which types of data might be sought from individuals when researching situational awareness, although the embedded-interactive view would suggest that data on the status of the world is required and the cognitive sub-systems view would suggest that data about the individual is also important. All three perspectives are underpinned by more general models of human cognitive functioning. Based on research into biological models of human physiology, Pedersen (1988) shows that the perceptual system has several levels of information processing. The first level requires people to detect signals and targets from an environment full of noise. People have to sift out the non-target information. Second, people have to organise the signals they detect into meaningful patterns of information. Finally, people have to understand these patterns, by sorting them into perceptual categories, and incorporate them into their existing belief and knowledge networks. Returning to the product-process dichotomy, the interactive sub-systems model and the perceptual cycle mainly concentrate on process whereas the three-level model is mainly concerned with product. In measuring situational awareness it is important that neither of these aspects is overlooked, as the latter is highly likely to be determined by the former.

\section{Loss of Situational Awareness}

As already introduced, it is suggested that loss of situational awareness is correlated with poor system performance. Endsley and colleagues, in particular, have gone on to consider the implication of losing situational awareness. They suggest that people who have lost situational awareness may be slower to detect problems with the system they are controlling as well as requiring additional time to diagnose problems and conduct remedial activities when they are finally detected (Endsley \& Kiris, 1995). Jones \& Endsley (1996) analysed 143 aviation incidents and compared the levels at which the flight crew and pilots made errors, as shown in table two. Both groups appear to make the largest proportion of errors at level 1 but air traffic controllers seem to make proportionally more errors than flight crew at level 3. This is probably due to two main factors: first, most of their job is about predicting future states and, second, they are required to track many objects in a dynamic problem space. 


\begin{tabular}{|l|c|c|}
\hline Levels/Personnel & Flight Crew & Air Traffic Controllers \\
\hline Level 1 SA & $77.4 \%$ & $72.4 \%$ \\
\hline Level 2 SA & $21.1 \%$ & $17.2 \%$ \\
\hline Level 3 SA & $1.5 \%$ & $10.4 \%$ \\
\hline
\end{tabular}

Table two. Percentage of situational awareness errors made at each level by flight crew and air traffic controller in the analysis of 262 errors committed in 143 incidents (data from Jones \& Endsley, 1996).

Jones \& Endsley (1996) also present a human error taxonomy based on the three-level model as shown in table three. The analysis shows the overall combined percentage of errors for both flight crew and air traffic controllers.

\begin{tabular}{|l|l|l|}
\hline LEVELS & Descriptions of error types & Percentages \\
\hline \multirow{4}{*}{ Level 1 SA } & Data not available & $13.0 \%$ \\
\cline { 2 - 3 } & Data hard to detect or discriminate & $11.1 \%$ \\
\cline { 2 - 3 } & Failure to observe or monitor data & $35.1 \%$ \\
\cline { 2 - 3 } & Misperception of data & $8.7 \%$ \\
\cline { 2 - 3 } & Forget data & $8.4 \%$ \\
\hline \multirow{3}{*}{ Level 2 SA } & Lack of, or incomplete, mental model & $6.9 \%$ \\
\cline { 2 - 3 } & Use of incorrect mental model & $6.5 \%$ \\
\cline { 2 - 3 } & Over-reliance on default values & $4.6 \%$ \\
\cline { 2 - 3 } & Other & $2.3 \%$ \\
\hline & Lack of, or incomplete, mental model & $0.4 \%$ \\
\cline { 2 - 3 } & Over-projection of current trends & $1.1 \%$ \\
\cline { 2 - 3 } & Other & $1.9 \%$ \\
\hline
\end{tabular}

Table three. Taxonomy of 262 errors based on the analysis of 143 aviation incidents (data from Jones \& Endsley, 1996).

Jones \& Endsley conclude that by far the largest proportion of errors result from the failure of the flight crew or air traffic controllers to observe or monitor data. It is possible that these errors might be reduced by better means of displaying the data in the first place and improved training in situational assessment strategies.

In another study of operational errors involving situational awareness, Dorso, Truitt, Hackworth, Crutchfield \& Manning (1998) compared errors made by air traffic controllers who had situational awareness with those who had lost it. Their studies 388 reports on operational reports filed in 1993. From these reports, expert judges rated $62 \%$ of the controllers as 'unaware' that an operational incident was developing and $38 \%$ as 'aware' of the situation but unable to rectify it in time. An analysis of the technical factors is shown in table four.

\begin{tabular}{|l|l|l|}
\hline Technical error type & Unaware & Aware \\
\hline Computer entry & 12.2 & 2.7 \\
\hline Flight progress strip updating & 8.4 & 9.9 \\
\hline Misidentification on radar display & 12.2 & 10.7 \\
\hline
\end{tabular}




\begin{tabular}{|l|l|l|}
\hline Inappropriate use of data displayed on radar display & 51.2 & 67.4 \\
\hline Communications & 28.9 & 13.3 \\
\hline Readback & 21.0 & 11.4 \\
\hline Co-ordination & 12.9 & 7.9 \\
\hline Inappropriate use of information exchanged in co-ordination & 5.0 & 4.1 \\
\hline Handover relief briefing & 3.8 & 0.7 \\
\hline
\end{tabular}

Table four. Percentages of technical errors for 'unaware' and 'aware' air traffic controllers (data from Durso et al., 1998). Note: an operational error could implicate more than one technical factor.

From the analysis presented in table four, it seems that 'aware' controllers are more likely to use displayed data inappropriately, whereas 'unaware' controllers are more likely to make errors on data entry, communications and readback. Durso et al (1998) went on to classify each of the errors in terms of the underlying psychological mechanisms of perception, attention, memory and decision making. If the person misread or misheard the information, the error was assigned to the 'perception' category. If the person was distracted or not attentive, the error was assigned to the 'attention' category. If the person could not recall, or confused, the information then the error was assigned to the 'memory' category. Finally, if there was poor interpretation, poor understanding, poor judgement, poor reasoning, or poor planning then the error was assigned to 'decision making'. An analysis of the psychological factors for the 'unaware' and 'aware' groups is shown in table five. 


\begin{tabular}{|l|l|l|}
\hline Psychological mechanism & Unaware & Aware \\
\hline Perception & 24 & 14 \\
\hline Attention & 26 & 24 \\
\hline Memory & 32 & 18 \\
\hline Decision making & 38 & 56 \\
\hline
\end{tabular}

Table five. Underlying psychological mechanisms assigned to technical errors (data from Durso et al., 1998). Note: an operational error could implicate more than one psychological mechanism, making the total percentage over 100.

As table five shows, 'aware' controllers are more likely to make errors associated with decision making, whereas 'unaware' controllers errors are much more evenly spread across the psychological mechanisms. At first sight it might appear worrying that more 'aware' controllers make more decision making errors. These figures are expressed as a proportion of the total number of errors however, and it is reasonable to suppose that the absolute number of errors reduces with increased situational awareness but there is a proportional shift in the types of errors made. This is a similar argument to that made about the effect of skill acquisition on human error rates (Reason, 1990).

On the basis of the evidence presented, it can be suggested that understanding the nature of situational awareness errors can be helpful in deciding upon strategies for developing effective counter-measures.

\section{Improving Situational Awareness}

Endsley (1995) argues that system design should try to support and enhance situational awareness. She proposed a set of interface design criteria for enhancing situational awareness:

(i) Reduce the requirement for people to make calculations.

(ii) Present data in a manner that makes level 2 SA (understanding) and level 3 SA (prediction) easier.

(iii) Organise information in a manner that is consistent with the persons goals.

(iv) Indicators of the current mode or status of the system can help the cue the appropriate situational awareness.

(v) Critical cues should be provided to capture attention during critical events.

(vi) Global situational awareness is supported by providing an overview of the situation across the goals of the operator.

(vii) System-generated support for projection of future events and states will support level 3 SA.

(viii) System design should be multi-modal and present data from different sources together rather than sequentially in order to support parallel processing of information.

Whilst most of these guidelines would generally seem indicative of good design, presenting them in terms of situational awareness can help provide a powerful frameof-reference. It also provides indicators that might not be as readily apparent if situational awareness was not to be considered. 
In a demonstration of the wider application of situational awareness concepts and methods, Gaba, Howard \& Small (1995) studied the cognitive processes of anaesthesiologists. They argue that situational awareness is a generic cognitive skill that is integral to all situations that require expert performance in dynamic, complex, and uncertain environments. As a skill, Gaba et al (1995) also propose that many aspects of situational awareness can be taught, such as:

(i) Practice in scanning relevant displays to maximise perception.

(ii) Use of expanded checklists to ensure that relevant data are not lost.

(iii) Explicit training in allocation of attention.

(iv) Practising multi-tasking rather than performing isolated tasks.

(v) Training in pattern recognition and pattern matching.

Whilst, on the face of it, these recommendations may seem a little obvious and confirm what was previously thought to be the case, situational awareness brings the ideas together under a single unifying concept. Some researchers have incorporated situational awareness training into crew resource management programmes (Salas, Prince, Bowers, Stout, Oser \& Cannon-Bowers, 1999). These programmes incorporate strategies for improving timely sampling of appropriate displays, dynamic workload distribution, communication and feedback, and tactics in emergency scenarios.

\section{Conclusions}

The initial review of the literature began with some critique of the usefulness of the concept of situational awareness. The response from flight crews, air traffic controllers and the National Transportation Safety Board seems to suggest that the ideas have proved to be of practical worth, whilst academic research still debates the definition and underlying theory. The theoretical debate hinges on whether situational awareness is a process or a product. The three-level model and interactive sub-systems emphasise product (i.e. the resultant state of situational awareness in the mind of the human operator) whereas the perceptual cycle emphasises process (i.e. the acts of acquiring situational awareness by the human operator). This debate is likely to rage for sometime. The three-level model seems to be the most developed approach, in terms of measures and interventions, although there is some controversy about the ideas underpinning it. Practical measures have been developed that can assess both the process of acquiring situational awareness and the product of situational awareness. Improvement of situational awareness seems to focus on two main strategies, either the design of the system interface to encourage better sampling and reduce the cognitive workload or training in situational awareness at the individual and team levels. As a topic for the future, situational awareness seems to have captured the imagination of both researchers and practitioners and would seem to have direct safety implications. Applications are spreading beyond aviation to include medicine, ground transportation, energy production, energy distribution, and process control. 


\section{References}

ADAMS M. J., TENNEY, Y. J. \& PEW R. W. 1995

SITUATION AWARENESS AND THE COGNITIVE MANAGEMENT OF COMPLEX-SYSTEMS.

HUMAN FACTORS 37 (1) 85-104

BEDNY, G. \& MEISTER, D. 1999

THEORY OF ACTIVITY AND SITUATION AWARENESS

INT J COGNITIVE ERGONOMICS 3 (1) 63-72

COOPER, G. E.., WHITE, M. D. \& LAUBER, J. K. 1980

RESOURCE MANAGEMENT ON THE FLIGHTDECK

NASA/INDUSTRY WORKSHOP, NASA CP-2120, NASA: USA.

DURSO F. T., TRUITT T. R. \& HACKWORTH C. A. 1998

EN ROUTE OPERATIONAL ERRORS AND SITUATION AWARENESS.

INT J AVIAT PSYCHOL 8 (2) 177-194

ENDSLEY, M. (1988)

DESIGN AND EVALUATION FOR SITUATIONAL AWARENESS

ENHANCEMENT

PROCEEDINGS OF THE HUMAN FACTORS SOCIETY 32nd ANNUAL MEETING (pp 97-101) SANTA MONICA: HFES.

ENDLSEY M. R. 1995

TOWARD A THEORY OF SITUATION AWARENESS IN DYNAMICSYSTEMS.

HUM FACTORS 37 (1) 32-64

ENDSLEY, M. R. \& SMOLENSKY, M. W. 1998

SITUATIONAL AWARENESS IN AIR TRAFFIC CONTROL: THE PICTURE

HUMAN FACTORS IN AIR TRAFFIC CONTROL

ENDSLEY M. R. \& KIRIS, E. O. 1995

THE OUT OF THE LOOP PERFORMANCE PROBLEM AND LEVEL OF CONTROL IN AUTOMATION.

HUM FACTORS 37 (2) 381-394

ENDSLEY, M. R. \& SMOLENSKY, M. W. 1998

SITUATIONAL AWARENESS IN AIR TRAFFIC CONTROL: THE PICTURE

HUMAN FACTORS IN AIR TRAFFIC CONTROL 
FLACH J. M. 1995

SITUATION AWARENESS - PROCEED WITH CAUTION.

HUMAN FACTORS 37 (1) 149-157

GABA D. M, HOWARD, S. K. 1995

SITUATION AWARENESS IN ANAESTHESIOLOGY

HUMAN FACTORS 37 (1) 20-31

GILSON, R. D. 1995

SITUATION AWARENESS - SPECIAL ISSUE PREFACE

HUMAN FACTORS 37 (1) 3-4

HARTEL, C. E. J.; SMITH, K. \& PRINCE, C. (1991)

DEFINING AIRCREW COORDINATION

SIXTH INTERNATIONAL SYMPOSIUM ON AVIATION

PSYCHOLOGY. COLUMBUS, OHIO.

JENSEN, R. S. 1997

THE BOUNDARIES OF AVIATION PSYCHOLOGY, HUMAN FACTORS, AERONAUTICAL DECISION MAKING, SITUATION AWARENESS, AND CREW RESOURCE MANAGEMENT.

INT J AVIAT PSYCHOL 7 (4) 259-267

JENTSCH, F., BARNETT, J. \& BOWERS C. A. 1999

WHO IS FLYING THIS PLANE ANYWAY? WHAT MISHAPS TELL US ABOUT CREW MEMBER ROLE ASSIGNMENT AND AIR CREW SITUATION AWARENESS.

HUM FACTORS 41 (1) 1-14

JONES D. G., \& ENDSLEY, M. R. 1996

SOURCES OF SITUATION AWARENESS ERRORS IN AVIATION

AVIAT SPACE ENVIR MD 67 (6) 507-512

KABER D. B. \& ENDSLEY M. R. 1997

OUT-OF-THE-LOOP PERFORMANCE PROBLEMS AND THE USE OF INTERMEDIATE LEVELS OF AUTOMATION FOR IMPROVED CONTROL SYSTEM FUNCTIONING AND SAFETY

PROCESS SAF PROG 16 (3) 126-131

NIESSER, U. 1976

COGNITION AND REALITY: PRINCIPLES AND IMPLICATIONS OF COGNITIVE PSYCHOLOGY

FREEMAN: SAN FRANCISCO. 
NORMAN DA. 1991

THE PROBLEM WITH AUTOMATION

PHIL. TRANS. ROYAL SOCIETY 327, 585-593

PEDERSEN, S, A. 1988

MODELLING THE BACKGROUND OF KNOWLEDGE AND BELIEF

IN: L. P. GOODSTEIN, H. B. ANDERSEN \& S. E. OLSEN (EDS)

TASKS, ERRORS AND MENTAL MODELS

TAYLOR \& FRANCIS: LONDON.

REASON, J. T. 1990

HUMAN ERROR

CAMBRIDGE UNIVERSITY PRESS: CAMBRIDGE

SARTER, N. B. \& WOODS, D. D. 1991

SITUATION AWARENESS: A CRITICAL BUT ILL DEFINED

PHENOMENON

INT J AVIATION PSYCHOLOGY, 1, 45-57.

SALAS, E., PRINCE, C. \& BAKER D. P. 1995

SITUATION AWARENESS IN TEAM PERFORMANCE -

IMPLICATIONS FOR MEASUREMENT AND TRAINING

HUM FACTORS 37 (1) 123-136

SALAS, E., PRINCE, C. \& BOWERS, C. A. 1999

A METHODOLOGY FOR ENHANCING CREW RESOURCE

MANAGEMENT TRAINING.

HUM FACTORS 41 (1) 161-172

SMITH, K. \& HANCOCK, P. A. 1995

SITUATION AWARENESS IS ADAPTIVE, EXTERNALLY DIRECTED CONSCIOUSNESS

HUM FACTORS 37 (1) 137-148

WOODS, D. D. (1988)

COPING WITH COMPLEXITY: THE PSYCHOLOGY OF HUMAN

BEHAVIOUR IN COMPLEX SYSTEMS

IN: L. P. GOODSTEIN, H. B. ANDERSEN \& S. E. OLSEN (EDS)

TASKS, ERRORS AND MENTAL MODELS

TAYLOR \& FRANCIS: LONDON.

ZSAMBOK, C. E. (1997)

NATURALISTIC DECISION MAKING: WHERE ARE WE NOW?

IN: C. E. ZSAMBOK \& G. KLEIN (EDS)

NATURALISTIC DECISION MAKING

LAWRENCE ERLBAUM: NEW JERSEY. 